\title{
Numerical Study of the Effect of a Turbulent Airflow on the Heat Transfer on Cuboid Food
}

\author{
${ }^{1}$ E. Martínez-Espinosa, ${ }^{2}$ M. Salinas-Vázquez, ${ }^{3} \mathrm{~W}$. Vicente, ${ }^{4} \mathrm{C}$. Lara-Guzman \\ ${ }^{1,2,3,4}$ Institute of Engineering of the National Autonomous University of Mexico, México City 04510
}

\begin{abstract}
A numerical simulation is conducted to study the effect of a turbulent airflow on heat transfer on cuboid food. The simulation is carried out with the Large Eddy Simulation approach. Periodic boundary conditions are implemented to represent a drying chamber as a single isolated zone where the phenomenon is conserved. Conjugate modelling is performed by coupling air-food phases by boundary conditions of continuity at the food interface. Numerical code is validated with empirical correlations of Nusselt number. Results show that low stream wise separations $(0.25)$ present the best and worst heat transfer. Therefore, the best heat transfer on the cuboid food is found at span wise distances higher than 0.5and stream wise separations higher than 0.25 . These separations are recommended to have a reasonable food drying control.
\end{abstract}

Keywords: Numerical simulation, LES, periodic boundary conditions, turbulent flow, heat transfer, food drying.

\section{INTRODUCTION}

Conjugate simulations on food drying reported in the open literature have been conducted in laminar flow, or turbulent flow with the Reynolds Averaged Navier-Stokes (RANS) approach. For instance, laminar flow simulations have been conducted in one-dimensional (Tang and Min [1]), twodimensional (Kaya et al. [2-4], De Bonis and Ruocco [5], Kim et al. [6], and Silva Júnior et al. [7], and Selimefendigil et al. [8]) and three-dimensional cases (Ateeque et al. [9], Chandra Mohan and Talukdar [10], Chandramohan [11-12], Curcio et al. [13], and Khan and Straatman [14]. Turbulent simulations have developed in two-dimensional (Sabarez [15], Kurnia et al. [16], Tzempelikos et al. [17], and Defraeye and Radu [18]) and three-dimensional studies Caccavale et al. [19], and Curcio et al. [20].

LES simulations allow a statistical study of flow and turbulence because instantaneous, fluctuating, and mean variables are available. Then Reynolds stresses, turbulent heat flows, and many other statistical variables can be obtained. Therefore, a conjugate heat and mass transfer simulation to model vegetable cuboids drying with the Large Eddy Simulation (LES) is performed. The implementation of periodic boundary conditions represents a cuboid vegetable (potato) inside an in-line arrangement. A potato cuboid, turbulent airstream $(\operatorname{Re} \approx 4200)$, and air temperature of $60\left[{ }^{\circ} \mathrm{C}\right]$ are injected into the chamber. The main objective is to study the effect of turbulent airflow on heat transfer of cuboid food, which can be applied to industrial drying chambers.

\section{PHENOMENON FORMULATION}

The phenomenon representation of heat and mass transfer in food drying is shown in Fig. 1. Conjugate modelling simultaneously solves heat and mass transport equations in external flow and inside the food. The external flow is modelled as a turbulent regime through the LES approach. Then governing equations of continuity, momentum, and energy are solved. Moisture concentration inside the food is represented by Fick law (pure diffusion). Mathematical conditions on the food interface are imposed by the complete continuity of the heat and mass fluxes. Energy flux considers the effect of moisture evaporation as studies performed by Ateeque et al. [9], Aversa et al. [21], and Curcio et al. [20]. Simulation represents a drying chamber by periodic boundary conditions in all directions of the computational domain. In these boundary conditions, the walls did not influence any direction. Then a drying chamber can be reduced to a single isolated zone (fraction of inline arrangement) in the fully developed zone where the phenomenon is conserved and calculation times are finite.

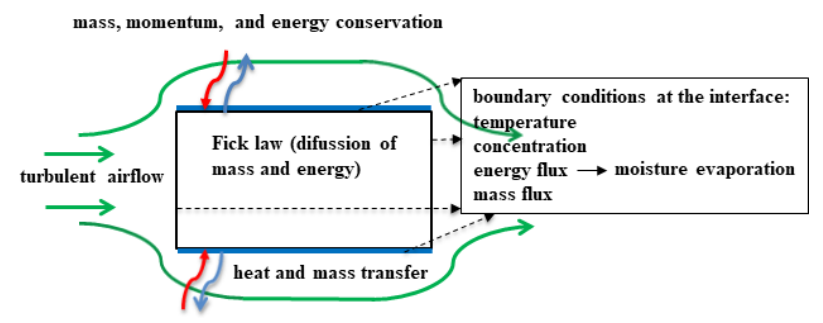

Figure 1: Phenomenon formulation in the simulation

\section{NUMERICAL SIMULATION}

The work simulates a cuboid potato of $\mathrm{Dx} 0.5 \mathrm{Dx} 0.5 \mathrm{D}$ $(04 \times 0.02 \times 0.02 \mathrm{~m}, \mathrm{D}=0.04 \mathrm{~m})$ in the $\mathrm{x}, \mathrm{y}$, and $\mathrm{z}$ directions, as shown in Fig. 2. Simulations consider a mainstream velocity $\mathrm{U} 0=2.5 \mathrm{~m} / \mathrm{s} \quad(\mathrm{Re} \approx 4200)$ and inlet air temperature $\left(\mathrm{T}_{0}=333.15 \mathrm{~K}\right)$. The representation of the inline food array in a 
ISSN (online): 2581-3048

cuboid food is done by periodic boundary conditions, as shown in Fig. 2.

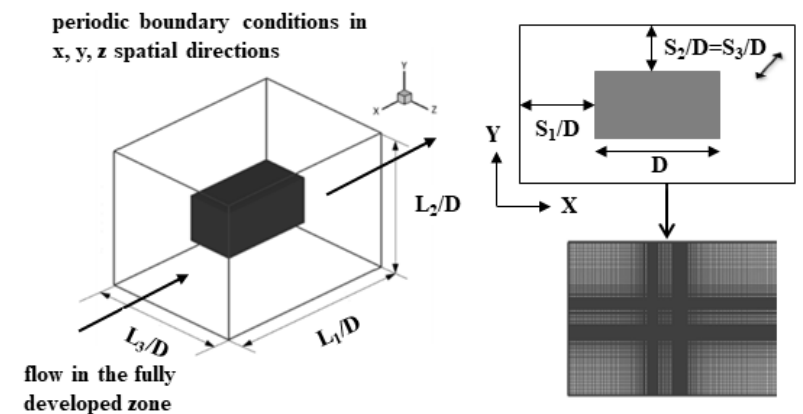

Figure 2: Geometrical characteristics in the computational domain

\subsection{Study case}

The geometrical characteristics of the computational domain and the location of the cuboid food are represented in Fig. 2. The stream wise and span wise spacing between solid body and walls of the computational domain is pointed out as $\mathrm{S}_{1} / \mathrm{D}$ and $\mathrm{S}_{2} / \mathrm{D}, \mathrm{S}_{3} / \mathrm{D}$ (the two transversal directions $\mathrm{S}_{3} / \mathrm{D}=\mathrm{S}_{2} / \mathrm{D}$ are the same). The dimensions of the computational domain (Fig. 2) are presented in dimensionless form as $\mathrm{L}_{1} / \mathrm{D}, \mathrm{L}_{2} / \mathrm{D}$, and $\mathrm{L}_{3} / \mathrm{D}$ in $\mathrm{x}, \mathrm{y}$, and $\mathrm{z}$ directions. A combination of twelve sizes of the computational domain and spacing between bodies are presented in Table 1.Then twelve simulations are conducted to study the effect of turbulence on heat and mass transfer.

Table 1: Dimensions used in simulation

\begin{tabular}{|l|l|l|l|l|}
\hline Case & $\mathbf{L}_{\mathbf{1}} / \mathbf{D}$ & $\begin{array}{l}\mathbf{L}_{\mathbf{2}} / \mathbf{D} \\
\mathbf{L}_{3} / \mathbf{D}\end{array}$ & $\mathbf{S}_{\mathbf{1}} / \mathbf{D}$ & $\begin{array}{l}\mathbf{S}_{2} / \mathbf{D} \\
\mathbf{S}_{3} / \mathbf{D}\end{array}$ \\
\hline 1 & 1.5 & 1.0 & 0.25 & 0.25 \\
\hline 2 & 2.0 & 1.0 & 0.5 & 0.25 \\
\hline 3 & 2.5 & 1.0 & 0.75 & 0.25 \\
\hline 4 & 3.0 & 1.0 & 1.0 & 0.25 \\
\hline 5 & 1.5 & 1.5 & 0.25 & 0.5 \\
\hline 6 & 2.0 & 1.5 & 0.5 & 0.5 \\
\hline 7 & 2.5 & 1.5 & 0.75 & 0.5 \\
\hline 8 & 3.0 & 1.5 & 1.0 & 0.5 \\
\hline 9 & 1.5 & 2.0 & 0.25 & 0.75 \\
\hline 10 & 2.0 & 2.0 & 0.5 & 0.75 \\
\hline 11 & 2.5 & 2.0 & 0.75 & 0.75 \\
\hline 12 & 3.0 & 2.0 & 1.0 & 0.75 \\
\hline
\end{tabular}

\subsection{Numerical details}

The simulation is performed in a homemade numerical code with the LES approach for turbulent airflow. The homemade code has been validated in different studies as Cubos-Ramírez et al. [22], Salinas-Vázquez et al. [23-24], Salinas-Vázquez and Métais [25].LES solves large grid scales and models the small scales, which are isotropic. The heat and mass diffusion inside cuboid food is modelled by Fick law, which is solved by a three-level fully-implicit finite difference scheme. The heat diffusion coefficient is constant, but the mass diffusion coefficient is temperature-dependent, calculated as a temperature function (Chandramohan [12]). The implementation of boundaries conditions is based on Poinsot and Lele [26]. Then initial conditions used in the simulation are velocity null, pressure, and temperature equal to the atmospheric values (reference values).Periodic boundary conditions are imposed in all directions $(\mathrm{x}, \mathrm{y}, \mathrm{z})$.

The grid resolution used in all simulations has a resolution of $200,100,100$ computational points in the $x, y$, and $z$ directions, see Fig. 2. Finally, simulation is validated in heat transfer with the experimental correlations of a global Nusselt number proposed by Iguarashi [27-28] for a square cylinder case. Numerical predictions show a global Nusselt number of $\mathrm{Nub} \approx 74$, which agrees with values of Nub between 71-101.

\section{RESULTS}

Discussion is focused on the turbulence kinetic energy and fluctuation velocities, which are related to heat and mass transfer by the turbulence, in dimensionless form. Fig. 3 presents turbulent kinetic energy $\left(k=\frac{1}{2}\left(\left\langle u^{\prime} u^{\prime}\right\rangle+\left\langle v^{\prime} v^{\prime}\right\rangle+\right.\right.$ $w^{\prime} w^{\prime}$ contours, where $u^{\prime}, v^{\prime}$, and $w^{\prime}$ are the fluctuation velocities in the $x, y, z$ directions. The maximum $k$ values are located near the body's front vertices, where separation of the boundary layers occurs. This separation promotes high stream wise velocity gradients, and heat and mass transfer could be favorable for food drying. Turbulent kinetic energy is high on the lateral walls $\left(1-1.3 \mathrm{U}_{0}\right.$ for $S_{2-3} / D=0.75$ and $1-1.5 \mathrm{U}_{0}$ for $S_{2-}$ $\left.{ }_{3} / D<0.75\right)$ and around the wake, as shown in Fig 3 . Then heat and mass transfer are intense at high $k$ values. Contour shows that as $S_{2-3} / D$ decreases, $k$ increases, and the flow's stream wise velocity between the bodies enhance. Heat transfer is more intense at $S_{2-3} / D$ separations less than 0.75 , but the drying process is more homogeneous at $S_{2-3} / D=0.75$, as seen in the heat transfer discussion.

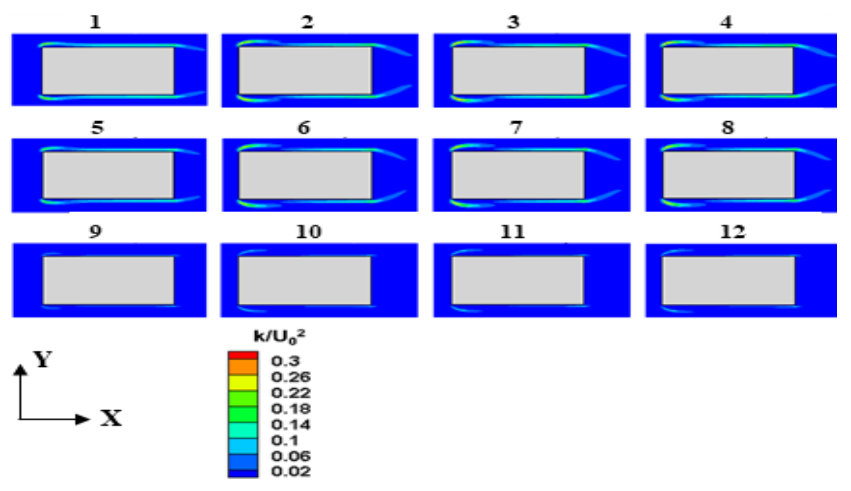

Figure 3: Dimensionless turbulent kinetic energy 
The root-mean-square streamwise velocity fluctuation $\left(u_{r m s}^{\prime}=\left\langle u^{\prime} u^{\prime}\right\rangle^{1 / 2}\right)$ measures the turbulence intensity in any direction. Fig. 4 shows a similar streamwise component $\left(u_{r m s}^{\prime}\right)$ behaviour as the turbulent kinetic energy contours (Fig. 3 ). The main source of $k$ is related to the streamwise velocity fluctuation by the separation of the boundary layer, which generates strong velocity gradients in the streamwise direction. High gradients of fluctuation velocities promote heat and mass transfer, but the cuboid food's heating could be non-homogeneous, which affects food drying. Other velocity fluctuation components as spanwise velocities ( $v_{r m s}^{\prime}$ contours in $x$-y planes are similar to $w_{r m s}^{\prime}$ contours in $x$ - $z$ planes) give additional information about the flow, especially from the body downstream where maximum values are found.

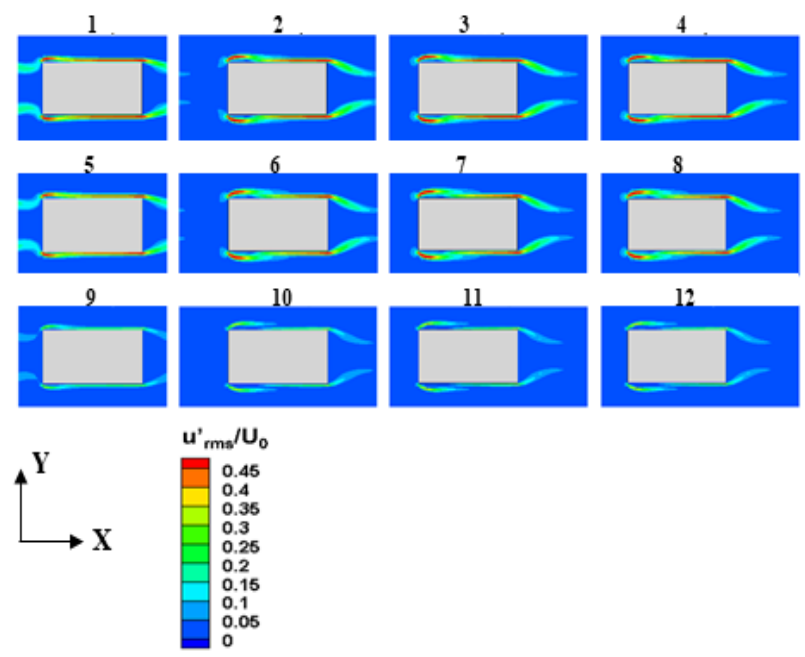

Figure 4: dimensionless $u^{\prime}$ velocities

The contours of spanwise velocity fluctuation $\left(v_{r m s}^{\prime}\right)$ in the middle of the $x-y$ plane are presented in Fig. 5, which shows the $v_{r m s}^{\prime}$ values are lower than $u_{r m s}^{\prime}$. This component's behavior changes behind the solid body, as a function of the spanwise and streamwise separations. Streamwise distance $S_{I} / D=0.25$ (cases 1,5 , and 9) presents almost null values of this component because the wake is weak and small. Intermediate distances $\left(\mathrm{S}_{1} / D>0.25\right.$ and $\mathrm{S}_{2} / D \leq 0.5 \mathrm{D}$ for cases 2 4,6 , and 7), exhibit an elongated contour around the wake as the $u_{r m s}^{\prime}$ contour and a central contour between the precedents. Due to the proximity between bodies, the wake's movement is limited. The highest values of the spanwise component are presented in the region of maximal streamwise velocity gradients (similar for the streamwise component). Cases at $\mathrm{S}_{1} / D>0.25$ and $\mathrm{S}_{2} / D \geq 0.5$ (8 and 10-12) present a behavior similar to a flow around a single body. The wake core moves freely, generating high values of spanwise $\left(v_{r m s}^{\prime}\right.$, $\left.w_{r m s}^{\prime}\right)$ as shown in two blue zones. The second zone of high $\left(v_{r m s}^{\prime}, w_{r m s}^{\prime}\right)$ is found in the body's front by boundary layer separation.

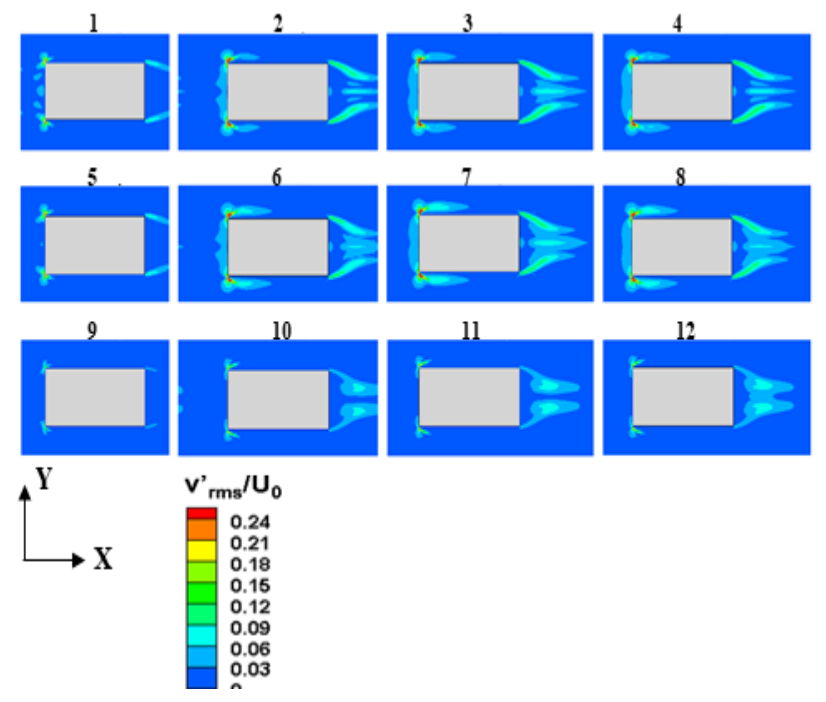

Figure 5: dimensionless $v^{\prime}$ velocities

The effect of $k$ and fluctuation velocities on heat transfer is presented in Fig. 6. The graph shows food cuboid heating (transient temperature difference between the bulk $T_{a}(\mathrm{t})$ air and the bulk solid body $\left.T_{s}(\mathrm{t})\right)$ at different drying times. Results show the best food cuboid heating $\left(\Delta T_{a-s}\right)$ corresponds to cases 1-4 and 10-12. The best and worst heating $\left(\Delta T_{a-s}\right)$ is found at streamwise distances $S_{I} / D=0.25$ (cases 1, 5, and 9). The heating is sensible by a blocking effect in the wake zone that affects heat transfer. Cases 10-12 present similar heating, which support the heat transfer tend to be homogeneous. So, these cases are the best option for food drying control.

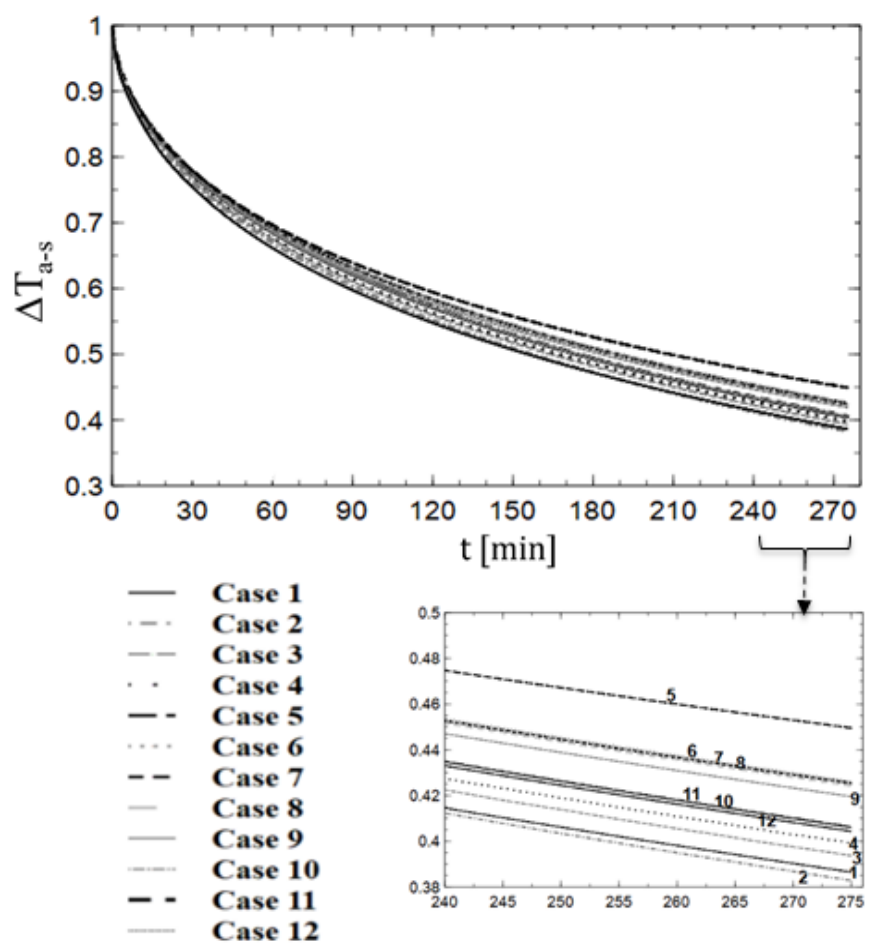

Figure 4: Dimensionless heating $\left(\Delta T_{a-s}\right)$ at different drying times 


\section{CONCLUSIONS}

Results show that the highest values of turbulent kinetic energy and velocities fluctuation are located on the body's front vertices, lateral walls, and around the wake. The heat and mass transfer could be favorable for food drying in these zones. The best cuboid food heating $\left(\Delta T_{a-s}\right)$ is presented incases 1-4 and 10-12. In cases 10-12, heating is high, and heat transfer tends to be more homogeneous than in other cases. Therefore, spanwise separations $S_{2-3} / D \geq 0.5$ and streamwise separations $S_{I} / D>0.25$ are recommended for better food drying control.

\section{ACKNOWLEDGEMENT}

We appreciate the financial support provided by the National Autonomous University of Mexico, DGAPA-PAPIIT TA100117.

\section{REFERENCES}

[1] Tang, Y., Min, J., 2019. Water film coverage model and its application to the convective air-drying simulation of a wet porous medium. Int. J. Heat Mass Transf. 131, 999-1008.

[2] KKaya, A., Aydin, O., Dincer, I., 2007. Numerical modeling of forced-convection drying of cylindrical moist objects. Numer. Heat Transf. Part A Appl. 51, 843-854.

[3] Kaya, A., Aydin, O., Dincer, I., 2008. Heat and mass transfer modeling of recirculating flows during air drying of moist objects for various dryer configurations. Numer. Heat Transf. Part A Appl. 53, 18-34.

[4] Kaya, A., Aydin, O., Dincer, I., 2008. Experimental and numerical investigation of heat and mass transfer during drying of Hayward kiwi fruits (Actinidia Deliciosa Planch). J. Food Eng. 88, 323-330.

[5] De Bonis, M. V., Ruocco, G., 2007. Modelling local heat and mass transfer in food slabs due to air jet impingement. J. Food Eng. 78, 230-237.

[6] Kim, D., Son, G., Kim, S., 2016. Numerical analysis of convective drying of a moist object with combined internal and external heat and mass transfer. Int. J. Heat Mass Transf. 99, 86-94.

[7] Silva Júnior, M.A.V., Rabi, J.A., Ribeiro, R., Dacanal, G.C., 2019. Modeling of convective drying of cornstarch-alginate gel slabs. J. Food Eng. 250, 9-17.

[8] Selimefendigil, F., Özcan, S., Hakan, Ç., 2019. Convective drying of a moist porous object under the effects of a rotating cylinder in a channel. J. Therm. Anal. Calorim. 141, 1569-1590.

[9] Ateeque, M., Udayraj, Mishra, R.K., Chandramohan, V.P., Talukdar, P., 2014. Numerical modeling of convective drying of food with spatially dependent transfer coefficient in a turbulent flow field. Int. J. Therm. Sci. 78, 145-157.

[10] Chandra Mohan, V.P., Talukdar, P., 2010. Three dimensional numerical modeling of simultaneous heat and moisture transfer in a moist object subjected to convective drying. Int. J. Heat Mass Transf. 53, 46384650 .

[11] Chandramohan, V.P., 2016. Experimental Analysis and Simultaneous Heat and Moisture Transfer with Coupled CFD Model for Convective Drying of Moist Object. Int. J. Comput. Methods Eng. Sci. Mech. 17, 59-71.

[12] Chandramohan, V.P., 2016. Numerical Prediction and Analysis of Surface Transfer Coefficients on Moist Object during Heat and Mass Transfer Application. Heat Transf. Eng. 37, 53-63.

[13] Curcio, S., Aversa, M., Calabro, V., Iorio, G., 2008. Simulation of food drying: FEM analysis and experimental validation. J. Food Eng. 87, 541-553.

[14] Khan, F.A., Straatman, A.G., 2016. A conjugate fluidporous approach to convective heat and mass transfer with application to produce drying. J. Food Eng. 179, 55-67.

[15] Sabarez, H.T., 2012. Computational modelling of the transport phenomena occurring during convective drying of prunes. J. Food Eng. 111, 279-288.

[16] Kurnia, J.C., Sasmito, A.P., Tong, W., Mujumdar, A.S., 2013. Energy-efficient thermal drying using impinging-jets with time-varying heat input - A computational study. J. Food Eng. 114, 269-277.

[17] Tzempelikos, D.A., Mitrakos, D., Vouros, A.P., Bardakas, A. V., Filios, A.E., Margaris, D.P., 2015. Numerical modeling of heat and mass transfer during convective drying of cylindrical quince slices. J. Food Eng. 156, 10-21.

[18] Defraeye, T., Radu, A., 2017. Convective drying of fruit: A deeper look at the air-material interface by conjugate modeling. Int. J. Heat Mass Transf. 108, 1610-1622.

[19] Caccavale, P., De Bonis, M.V., Ruocco, G., 2016. Conjugate heat and mass transfer in drying: A modeling review. J. Food Eng. 176, 28-35.

[20] Curcio, S., Aversa, M., Calabro, V., Iorio, G., 2008. Simulation of food drying: FEM analysis and experimental validation. J. Food Eng. 87, 541-553.

[21] Aversa, M., Curcio, S., Calabrò, V., Iorio, G., 2007. An analysis of the transport phenomena occurring during food drying process. J. Food Eng. 78, 922-932.

[22] Cubos-Ramírez, J.M., Ramírez-Cruz, J., SalinasVázquez, M., Vicente-Rodríguez, W., MartínezEspinosa, E., Lagarza-Cortés, C., 2016. Efficient two- 
ISSN (online): 2581-3048

Volume 6, Issue 2, pp 23-27, February-2022

https://doi.org/10.47001/IRJIET/2022.602005

phase mass-conserving level set method for simulation of incompressible turbulent free surface flows with large density ratio. Computers \& Fluids 136, 212-227.

[23] Salinas-Vázquez, M., de la Lama, M.A., Vicente, W., Martínez, E., 2011. Large Eddy Simulation of a flow through circular tube bundle. Appl. Math. Model. 35, 4393-4406.

[24] Salinas-Vázquez, M., Vicente, W., Martínez, E., Barrios, E., 2011. Large eddy simulation of a confined square cavity with natural convection based on compressible flow equations. Int. J. Heat Fluid Flow $32,876-888$.
[25] Salinas-Vázquez, M., Métais, O., 2002. Large-eddy simulation of the turbulent flow through a heated square duct. J. Fluid Mech. 453, 201-238.

[26] Poinsot, T.J., Lele, S.K., 1992. Boundary Conditions for Direct Simulations Compressible Viscous Flows. J. Comput. Phys. 101, 104-129.

[27] Iguarachi T., 1985, Heat transfer from a square prism to an air stream, Journal of Heat and Mass transfer, 28, 175-181.

[28] Iguarachi T., 1986, Local heat transfer from a square prism to an air stream, Journal of Heat and Mass transfer, 29, 777-784.

\section{Citation of this Article:}

E. Martínez-Espinosa, M. Salinas-Vázquez, W. Vicente, C. Lara-Guzman, "Numerical Study of the Effect of a Turbulent Airflow on the Heat Transfer on Cuboid Food" Published in International Research Journal of Innovations in Engineering and Technology - IRJIET, Volume 6, Issue 2, pp 23-27, February 2022. Article DOI https://doi.org/10.47001/IRJIET/2022.602005 